\title{
DIRECTLY-COUPLED GAS TURBINE PERMANENT MAGNET GENERATOR SETS FOR PRIME POWER GENERATION ON BOARD ELECTRIC SHIPS
}

\author{
By: \\ S. Vijlee \\ A. Ouroua \\ L.N. Domaschk \\ J.H. Beno
}

IEEE Electric Ship Technologies Symposium (ESTS 2007), Arlington, Virginia, U.S.A., May 21-23, 2007.

PR 447

Center for Electromechanics

The University of Texas at Austin

PRC, Mail Code R7000

Austin, TX 78712

(512) 471-4496

03/01/2007 


\title{
Directly-Coupled Gas Turbine Permanent Magnet Generator Sets for Prime Power Generation On Board Electric Ships
}

\author{
S.Z. Vijlee, A. Ouroua, L.N. Domaschk, and J.H. Beno
}

\begin{abstract}
Prime power generation on board all-electric ships presents several options that affect fuel consumption, power density, operational effectiveness, and survivability. A study that aims at understanding the effects of some of these options has been conducted and results are reported in this paper. It is found that direct coupling of gas turbines to permanent magnet generators reduces system mass and volume significantly as compared to electric power generation systems installed on present-day navy ships. Furthermore, it is found that a significant benefit this topology brings is a reduction in gas turbine air duct volume if the compact gen-set units are relocated on or near the ship's upper decks. In addition, a combinatory analysis revealed that the choice of the number of generating units and their respective power levels has a significant influence on overall efficiency.
\end{abstract}

Index Terms-Electric ship, gas turbines, permanent-magnet generators, power generation.

\section{INTRODUCTION}

Electric power needed on board future naval platforms is typically an order of magnitude larger than that in present-day navy ships. This ten-fold increase in electric prime power requires the addition of large generators and other power conditioning equipment. Consequently, improving power density levels, as compared to those found in land-based power plants is crucial for an effective all-electric naval platform.

Options when choosing a power plant for an electric ship include selection of:

- prime mover type

- number of prime movers

- coupling method between prime mover and generator

- type and topology of the generator

- prime mover and generator power and speed

- generation voltage and frequency

This work was supported by a grant from the Office of Naval Research, US Navy.

S. Vijlee (email: shazib.z.vijlee@boeing.com) is presently with Boeing, Seattle, WA. A. Ouroua (e-mail: a.ouroua@mail.utexas.edu), L.N. Domaschk (email:1domaschk@mail.utexas.edu), and J.H. Beno (email: j.Beno@mail.utexas.edu) are with The Center for Electromechanics, The University of Texas at Austin, 1 University Station R7000, Austin, TX 78712 USA.
- AC or DC distribution method

- mode of operation during given mission

- installation location on the ship.

All the aforementioned factors affect fuel consumption, power density, operational effectiveness, and survivability. Our work in this area aims at providing a comprehensive analysis of an $80 \mathrm{MW}$ prime power generation system sized for current projection of power levels in future all-electric destroyers. Specifically, the system under consideration in this study is based on directly-coupled gas turbines and permanent-magnet generators. A description of the topology is given in Section II.

An obvious benefit in using direct coupling stems from the removal of the gear box, but the use of permanent-magnet excitation in synchronous generators allows a considerable reduction in size and improvement in efficiency as compared to conventional wound-rotor generators (which require an exciter that adds to size and losses). In addition, direct coupling allows the generator to run at the highest speed possible and results in a smaller size since output power of synchronous generators is directly proportional to speed. A description of the permanent-magnet generators is given in Section IV. This high speed advantage, however, is limited by the gas turbine power level. As will be shown in Section III, gas turbine rated speed decreases as rated power increases.

Because propulsion load consumes up to $90 \%$ of total installed power through variable $\mathrm{AC}$ drives, power conversion from fixed frequency $\mathrm{AC}$ to variable frequency and amplitude is necessary. Motor drives of interest (such as those using the PWM scheme) require that power be converted to DC form. Consequently, the existence of a high power DC bus onboard all-electric ships is a requirement and not a choice. Furthermore, in order to have an integrated power system where power generated by any unit can be used by any load onboard, all generating units must have rectifiers. Therefore, high-power rectifiers are essential components that require special attention due to their highly non-linear load characteristics. A detail description of these rectifiers is given in Section V.

Another significant benefit in using this topology is related to the possible reduction of gas turbines' air duct volume. In fact, due to the inherent operation of gas turbines, intake and exhaust ducts are necessary and tend to occupy large volumes 
since they must extend all the way to the ship upper decks. By relocating some of the generating units to upper deck levels, a direct reduction in total duct size is achieved, thereby improving power density. Results of an analysis of power unit location using ship and gas turbine generator set models are presented in Section VI. Finally, a fuel consumption analysis for an $80 \mathrm{MW}$ all-electric ship with known mission profile is given in Section VII. The results are summarized in Section VIII.

\section{TOPOLOGY}

In present-day navy destroyers, electric power is typically produced by a system of three gas turbine generator sets coupled through gear boxes to reduce the frequency to $60 \mathrm{~Hz}$. The power level of the gen-sets is typically 3 to $5 \mathrm{MW}$ each and the electric generators are conventional wound-field synchronous machines, often with a low number of poles ( 2 to 4). The gear box, the field excitation system, and the low-pole count all contribute significantly to the size of the gen-set and the first two factors are particularly detrimental to the overall efficiency. A similar power plant architecture at the $80 \mathrm{MW}$ power level required for future destroyers would be too large and inefficient. One approach in addressing this challenge is to look at power plants based on gas turbines that are directly coupled to permanent-magnet generators. The configuration of interest is shown in Fig. 1 where a power rectifier block is added to form a complete system. Further discussions relevant to this topic can be found in [1]-[4].

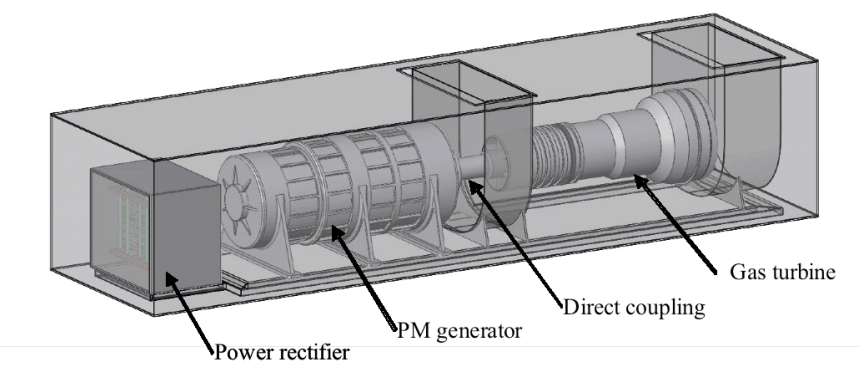

Fig. 1. Basic topology of directly-coupled gas turbine generator sets

The system shown in Fig. 1 represents a 5 MW gen-set with a high-speed generator directly coupled to an existing commercial gas turbine spinning at $\sim 15,000 \mathrm{rpm}$. A detailed study of such a system which includes an additional inverter that provides $4.16 \mathrm{kV} / 60 \mathrm{~Hz}$ output voltage showed that a weight saving of more than $50,000 \mathrm{lb}$ is achieved as compared to an existing conventional system [5].

\section{GAS TURBINE}

Gas turbine engines are thermodynamic turbomachinery that convert fluid and fuel energy into mechanical energy. They are widely used to propel aircraft and ships because of their compactness and reliability. However, they are inefficient and require expensive fuel. In order to determine the different relationships among power, speed, efficiency, and size, a detailed analysis of a simple-cycle gas turbine has been completed within the course of this study. The main results that allowed the derivation of the important relationship between gas turbine speed and power are summarized here and details of the analysis can be found in [6]. The simple-cycle gas turbine analyzed consists of a compressor, a burner, and a turbine.

A schematic of a single-shaft gas turbine where the compressor and the turbine share a single shaft is shown in Fig. 2.

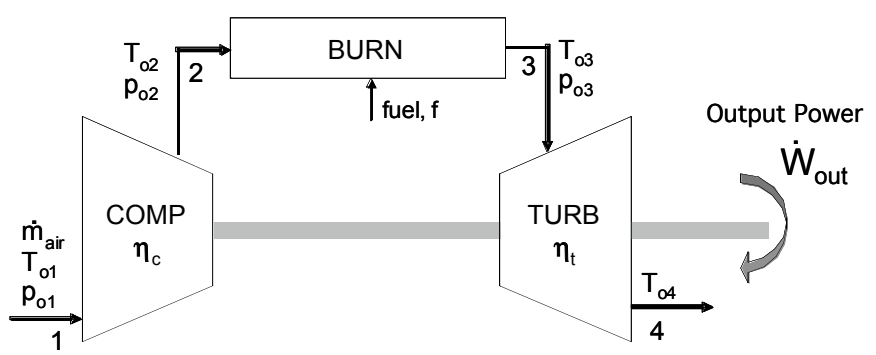

Fig. 2. Simple-cycle, single-shaft gas turbine engine.

Some of the turbine power is used to drive the compressor while the remaining power is converted to mechanical power through the shaft. The output shaft power is then:

$$
\dot{W}_{\text {out }}=\dot{W}_{\text {turbine }}-\dot{W}_{\text {compressor }}
$$

With the $1^{\text {st }}$ law of thermodynamics and assuming an isentropic process, steady state and steady flow, constant specific heat ( $c_{p}$ and $\gamma=$ constant), and neglecting heat loss, the output power is [6]:

$$
\dot{W}_{\text {out }}=\dot{m}_{\text {air }}(1+f) c_{p, t}\left(T_{o 4}-T_{o 3}\right)-\dot{m}_{\text {air }} c_{p, c}\left(T_{o 2}-T_{o 1}\right)
$$

where $m_{\text {air }}$ is the air flow rate, $f$ the fuel-air ratio, and the temperatures, as defined on Fig. 2, are:

$$
\begin{aligned}
& T_{o 2}=T_{o 1}\left\{\frac{1}{\eta_{c}}\left[\left(\frac{p_{o 2}}{p_{o 1}}\right)^{\frac{\gamma_{c}-1}{\gamma_{c}}}-1\right]+1\right\} \\
& T_{o 4}=T_{o 3}\left\{1-\eta_{t}\left[1-\left[\left(\frac{p_{o 3}}{p_{o 2}}\right)\left(\frac{p_{o 2}}{p_{o 1}}\right)\right]^{\frac{1-\gamma_{t}}{\gamma_{t}}}\right]\right\}
\end{aligned}
$$

The turbine inlet temperature $\mathrm{T}_{03}$ is a critical factor that affects engine output power and efficiency. The development of new material and cooling techniques of turbine blades present major challenges for improving power density and efficiency of gas turbines. 
The specific work $w$ is given by [6]:

$$
\begin{aligned}
& w=\frac{\dot{W}_{\text {out }}}{\dot{m}_{\text {air }}}=(1+f) c_{p, t} T_{o 3}\left\langle\eta_{t}\left\{1-\left[\left(\frac{p_{o 3}}{p_{o 2}}\right)\left(\frac{p_{o 2}}{p_{o 1}}\right)\right]^{1-\gamma_{t}} \gamma_{t}^{\gamma_{t}}\right\}-\right. \\
& c_{p, c} T_{o 1}\left\{\frac{1}{\eta_{c}}\left[\left(\frac{p_{o 2}}{p_{o 1}}\right)^{\frac{\gamma_{c}-1}{\gamma_{c}}}-1\right]\right\}
\end{aligned}
$$

The maximum specific work is obtained at a certain compression ratio $P_{02} / P_{01}$ for given operating parameters. Using the maximum specific work $w_{\max }$, the working fluid (air) velocity $V$ and density $\rho$, the blades' outer $\left(R_{t}\right)$ and inner $\left(R_{h}\right)$ radii, the air mass flow rate can be written as [6]:

$$
\dot{m}_{\text {air }}=\frac{\dot{W}_{\text {out }}}{w_{\max }}=\rho V \pi R_{t}^{2}\left(1-\zeta^{2}\right)
$$

where $\varsigma=\frac{R_{h}}{R_{t}}$. The outer radius of the blade is then:

$$
R_{t}=\sqrt{\dot{W}_{\text {out }} / w_{\max } \rho V \pi\left(1-\zeta^{2}\right)}
$$

The blades' outer radii and speed are constrained by stresses while the air flow velocity needs to be kept sub-sonic in order to avoid shockwaves and the losses associated with them. The Mach number $M$ needs to be limited to a maximum value of 1 :

$$
M=\sqrt{\frac{\left(\omega R_{t}\right)^{2}+V^{2}}{\gamma R T}} \leq M_{\text {limit }} \approx 1
$$

Using this expression for $M_{\text {lim }}=1$ and substituting for $R_{t}$, the blades' and therefore the shaft's angular velocity is:

$$
\omega=\sqrt{\frac{\left(M_{\lim }^{2} \gamma R T-V^{2}\right) w_{\max } \rho V \pi\left(1-\zeta^{2}\right)}{\dot{W}_{\text {out }}}}
$$

A plot of shaft velocity $\omega(\mathrm{rpm})$ vs. output power is shown in Fig. 3. Also in Fig. 3 are values for existing commercial turbines [7]. The results show a good agreement between theory and actual values of shaft speed as a function of power given the simple-cycle and single-shaft analysis using basic thermodynamics laws and limitations on blades' stresses and air flow velocity. This analysis demonstrates that indeed high power gas turbines require large sizes which, in turn, result in lower speeds. Therefore, for a given power level, increasing the speed does not allow a smaller gas turbine size as is the case for synchronous generators.

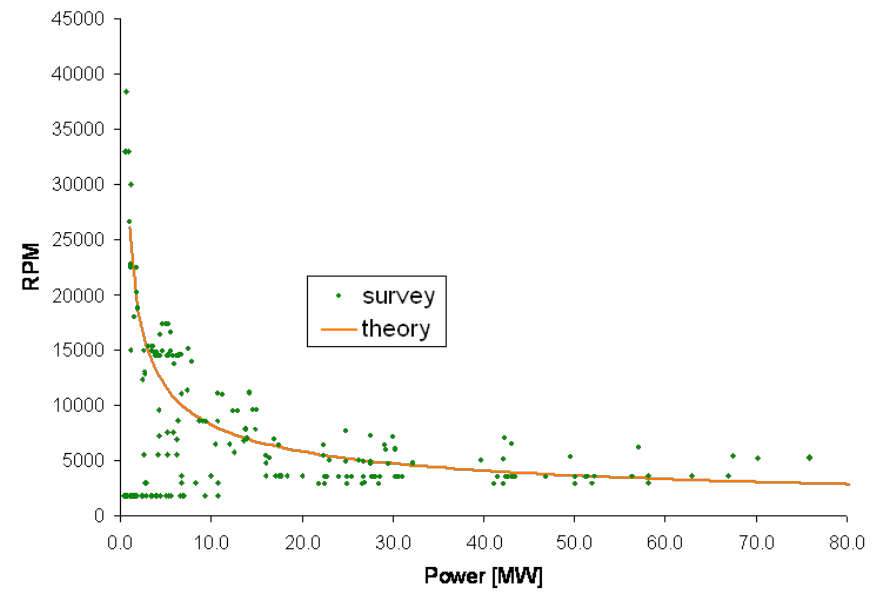

Fig. 3. Gas turbine speed vs. power.

\section{PERMANENT-MAGNET GENERATORS}

There are several permanent-magnet topologies that include radial, axial, and transverse flux topologies with variants in the way magnets are mounted or imbedded in the rotor. These topologies eliminate the need of an excitation winding and reduce the overall losses and size of the rotor.

In this study we considered the surface-mounted radial flux permanent-magnet topology. In this topology, magnets are mounted on the surface of the rotating shaft and held in place by a composite banding. Fig. 4 gives a simple description.

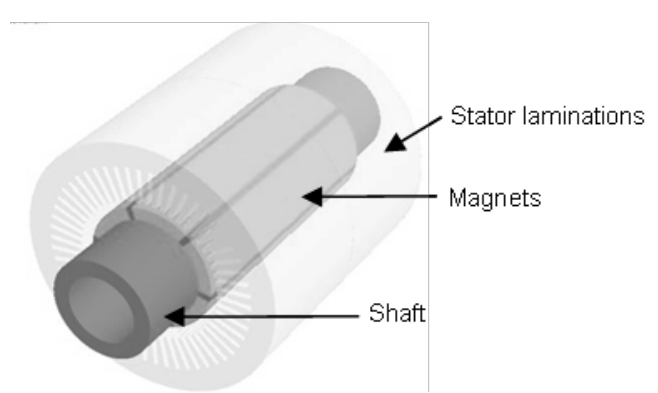

Fig. 4. Surface-mounted radial flux topology (banding not shown).

Unlike gas turbines where shaft speed decreases with increasing power, the output power of a synchronous generator is directly proportional to its shaft speed as can be seen in the general power equation:

$$
\text { Power }=k D^{2} l B A f_{m}
$$

where:

$$
\begin{aligned}
D & =\text { air gap diameter } \\
l & =\text { active length } \\
B & =\text { magnetic loading (air gap flux density) } \\
A & =\text { electric loading (line current density) } \\
f_{m} & =\text { mechanical frequency } \\
k & =\text { proportionality constant }
\end{aligned}
$$


Increasing generator speed is therefore advantageous in reducing size. For low to intermediate gas turbine power (1 to $15 \mathrm{MW}$ ) where shaft speed is higher than the conventional $3600 \mathrm{rpm}$, the high speed advantage is effective in reducing the generator size when direct coupling is considered. This is particularly true for low power engines (1 to $5 \mathrm{MW}$ ) where speed is $\sim 15,000 \mathrm{rpm}$ or higher.

The $5 \mathrm{MW}$ gen-set referred to earlier (Fig. 1.) includes a 6.25 MVA, 15,000 rpm, $750 \mathrm{~Hz}$, 9-phase generator with magnetic bearings. Fig. 5 gives an overview of the generator with magnetic bearings assembly.

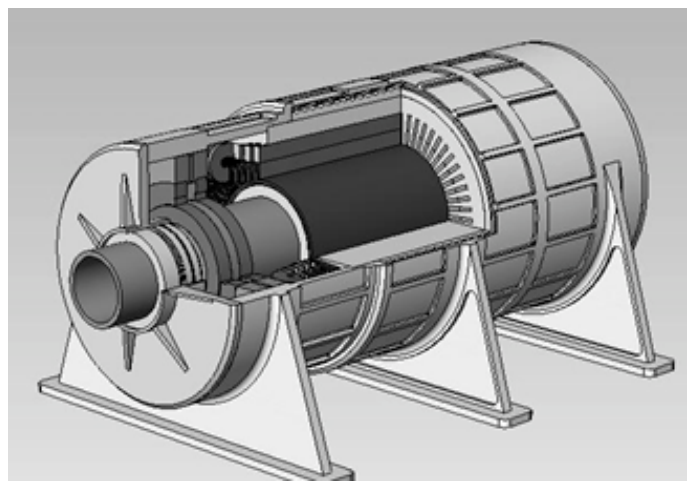

Fig. 5. 6.25 MVA permanent-magnet generator.

In order to determine component ratings and size of potential power generating units for an $80 \mathrm{MW}$ electric ship, we studied four other gas turbine-generator sets. The five genset systems are:

- 5 MW 15,000 rpm PM generator coupled with MT5 gas turbine.

- $11 \mathrm{MW}$ 11,000 rpm PM generator coupled with Solar 100 gas turbine.

- $\quad 15$ MW 7,900 rpm PM generator coupled with LM1600 gas turbine.

- 20 MW 3,600 rpm PM generator coupled with LM2500 gas turbine.

- $\quad 40 \mathrm{MW} \mathrm{3,600} \mathrm{rpm} \mathrm{PM} \mathrm{generator} \mathrm{coupled} \mathrm{with} \mathrm{MT30}$ gas turbine.

Fig. 6 is a general view of the 5 gen-sets that allows a relative comparison. Table I gives the corresponding weights and volumes.

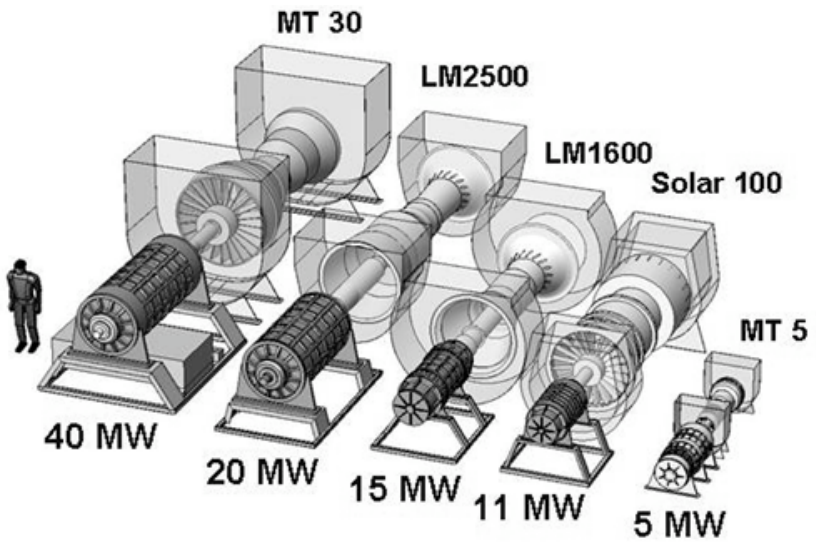

Fig. 6.5 directly-couple gas turbine-permanent magnet generator sets.
TABLE I

PRIME POWER GEN-SET COMPONENT VOLUMES AND WEIGHTS

\begin{tabular}{|c|c|c|c|c|c|c|}
\hline & \multicolumn{2}{|c|}{ Generators } & Turbines & \multicolumn{2}{c|}{$\begin{array}{c}\text { Turbines \& } \\
\text { Generators }\end{array}$} & Gen-sets \\
\hline $\begin{array}{c}\text { Power } \\
(\mathrm{MW})\end{array}$ & $\begin{array}{c}\text { Weight } \\
(\mathrm{kg})\end{array}$ & $\begin{array}{c}\text { Volume } \\
\left(\mathrm{m}_{3}\right)\end{array}$ & $\begin{array}{c}\text { Volume } \\
\left(\mathrm{m}_{3}\right)\end{array}$ & \multicolumn{2}{|c|}{ Volume (m3) } & $\begin{array}{c}\text { Volume } \\
\left(\mathrm{m}_{3}\right)\end{array}$ \\
\hline & & & Enclosure & Enclosure & Ducts & \\
\hline $\mathbf{5}$ & 1700 & 2.34 & 2.99 & 5.33 & 3.98 & 9.31 \\
\hline $\mathbf{1 1}$ & 2700 & 7.25 & 26.33 & 33.58 & 78 & 111.58 \\
\hline $\mathbf{1 5}$ & 5000 & 13.23 & 19.25 & 32.48 & 84 & 116.48 \\
\hline $\mathbf{2 0}$ & 9000 & 33.37 & 35 & 68.37 & 128 & 196.37 \\
\hline $\mathbf{4 0}$ & 13030 & 38.4 & 51.06 & 89.6 & 172.5 & 262.1 \\
\hline
\end{tabular}

\section{POWER CONVERSION}

Power distribution topology plays a major role in the choice of the power system architecture in an all-electric ship. The issue of using $\mathrm{AC}$ or DC distribution has been debated for several years while practical considerations show that both approaches have advantages and disadvantages [8,9]. Some of the factors that affect the selection of the most effective power plant architecture are: use of high-power transformers; present limitations of high-power DC switchgears; safety concerns and reliability issues related to level of distribution voltage; and size of cables and their associated losses.

The multitude of AC and DC loads makes both forms of power prevalent onboard navy ships. However, the zonal electric distribution system that is advocated by power designers requires that prime power generation be located in different zones in the ship. The ability to transfer power to other zones is required in case of emergencies that need a quick power system reconfiguration for ship survival. The buses that insure this transfer of power between various zones can be either AC or DC buses and the selection of appropriate bus type for specific ships with specific missions and requirements is not obvious. Since in our work on gas turbinegenerator sets we have used permanent-magnet generators operating with the highest speed possible, the resulting frequencies of the output power are higher than the conventional $60 \mathrm{~Hz}$ and differ from unit to unit. Therefore, connecting such generators in parallel to a common AC bus would require the use of frequency transformers (assuming the generation voltage level is the same for all units otherwise voltage transformers would also be necessary). If DC distribution is assumed, however, then all that is required is a rectifier connected to the output of each generator.

In order to determine the size and performance of power rectifiers in the 5 to $40 \mathrm{MW}$ range, we conducted a design study of 6-, 12-, and 18-pulse diode rectifiers. All power rectifiers were designed for $6.6 \mathrm{kV}$ generator output voltage chosen to adapt to current trends in navy requirements. The power diodes are selected from a set of diodes obtained through a general survey of commercial diodes throughout the world. The ratings of the most performing diodes are shown in Fig. 7. For the 6-pulse rectifiers, a Eupec device (D 2601N [10]) was chosen with $8 \mathrm{kV}$ and $3 \mathrm{kA}$ rating when operated with a $55^{\circ} \mathrm{C}$ heat sink temperature. A safety margin of two in 
voltage requires three diodes in series for each of the six diode sets. For simplicity, snubbers were not considered in this analysis of passive power rectifiers. The 6-pulse rectifier circuit for the $40 \mathrm{MW}$ unit is shown in Fig. 8.

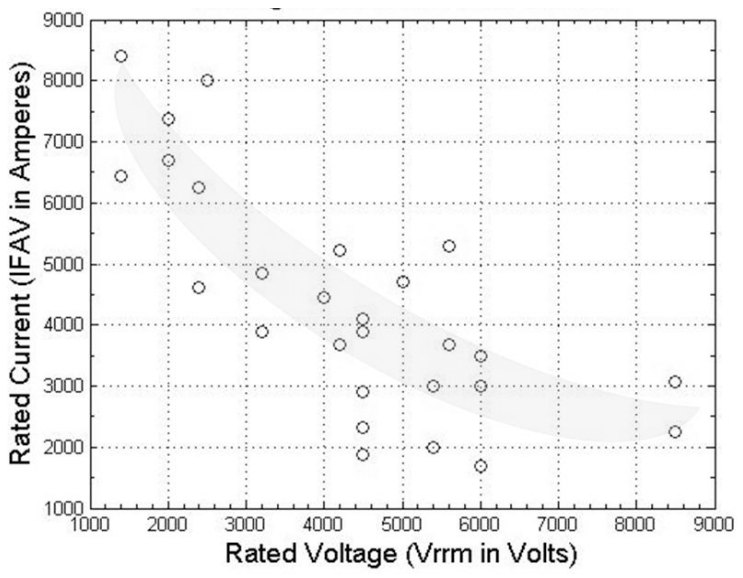

Fig. 7. Commercial power diode ratings.

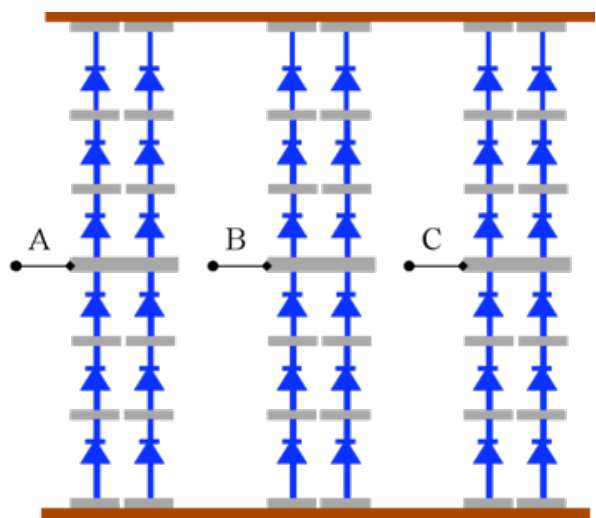

Fig. 8. 6-pulse rectifier circuit for the $40 \mathrm{MW}$ unit.

The assembled $5 \mathrm{MW} 6.6 \mathrm{kV}$ diode rectifier is shown in Fig. 9. It has a volume of $0.24 \mathrm{~m}^{3}$ and weighs $159 \mathrm{~kg}$. The power diodes are rated to operate with a heat sink temperature of $55^{\circ} \mathrm{C}$ which corresponds to a junction temperature of $60^{\circ} \mathrm{C}$ for the chosen Eupec device. At higher junction temperatures, the current the power diode can support drops significantly. It is therefore important to insure a reliable cooling system. The heat sinks are water-cooled and are designed with enough cooling channels to maintain the required temperature. A heat sink model and results of 2-D FEA thermal analysis (which establish a cooling flow rate of $0.77 \mathrm{gpm}$ for a coolant temperature of $45^{\circ} \mathrm{C}$ ) are shown in Fig. 10. The thermal design of the rectifiers is an important factor because it determines the cooling load required from the ship thermal management system. It also affects the size of the rectifier due to the cooling manifold which includes water inlets and outlets and their mechanical support.

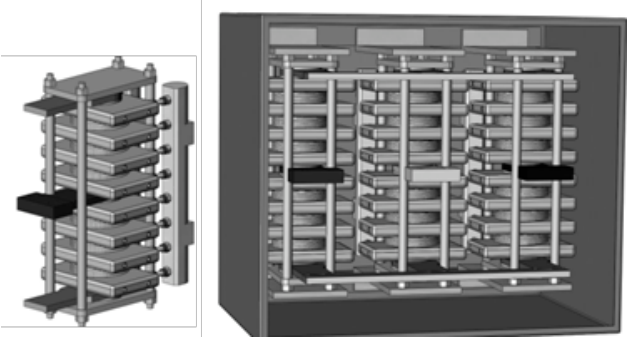

Fig. 9. 1-phase leg and assembly of the 5 MW 6-pulse rectifier.

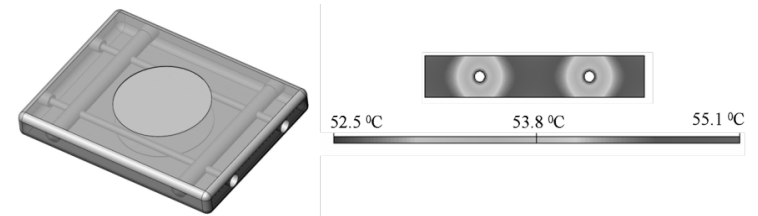

Fig. 10. 3-D model and temperature distribution in $5 \mathrm{MW}$ rectifier heat sinks.

Under normal operations, the rectifier draws non-linear currents from the generator and distorts its voltage waveform. This harmonic distortion is detrimental to the generator as well as to other AC loads connected to it. To reduce this harmonic distortion multi-pulse rectifiers are often used. These are basically sets of 6-pulse rectifiers connected in series or separately, depending on the load. Matlab/Simulink models are used to calculate the total harmonic distortion (THDs) for the 6- and 12-pulse designs for all five rectifier units. A 12pulse model for the $5 \mathrm{MW}$ rectifier is shown in Fig. 11 and the results when the generators are delivering full power are summarized in Table II.

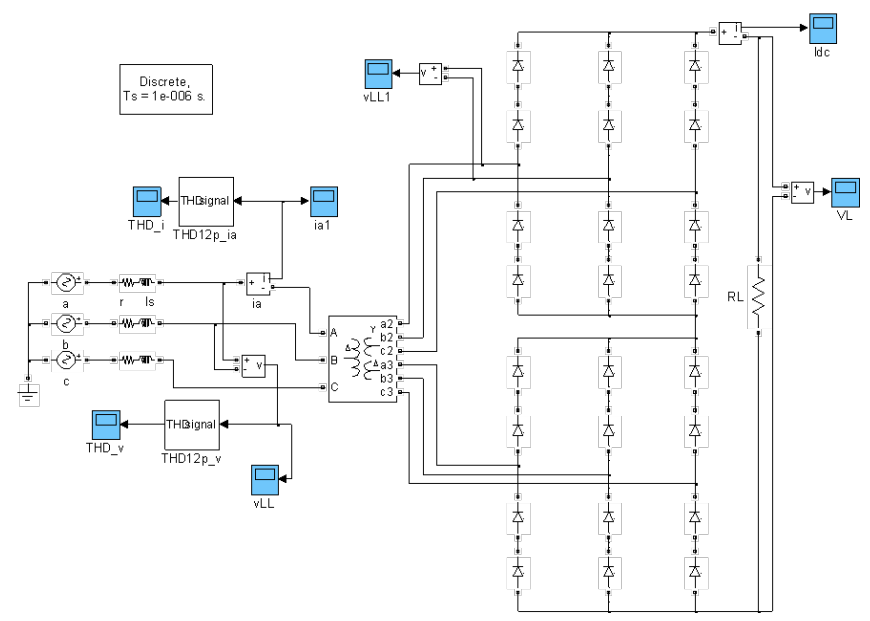

Fig. 11. Matlab/Simulink model of 12-pulse rectifier. 
TABLE II

TOTAL HARMONIC DISTORTIONS FOR 6- AND 12-PULSE RECTIFIERS

\begin{tabular}{|c|c|c|c|c|c|c|}
\hline & \multicolumn{3}{|c|}{ 6-Pulse } & \multicolumn{3}{c|}{ 12-Pulse } \\
\hline $\begin{array}{c}\text { Power } \\
\text { (MW) }\end{array}$ & $\begin{array}{c}\text { Diode } \\
\text { count }\end{array}$ & $\begin{array}{c}\text { THD } \\
(\%) \\
\text { Current }\end{array}$ & $\begin{array}{c}\text { THD } \\
(\%) \\
\text { Voltage }\end{array}$ & $\begin{array}{c}\text { Diode } \\
\text { count }\end{array}$ & $\begin{array}{c}\text { THD } \\
(\%) \\
\text { Current }\end{array}$ & $\begin{array}{c}\text { THD } \\
(\%) \\
\text { Voltage }\end{array}$ \\
\hline 5 & 18 & 18.4 & 25 & 24 & 5.4 & 14.5 \\
\hline 11 & 18 & 19.5 & 25 & 24 & 3.5 & 14.6 \\
\hline 15 & 18 & 22.7 & 22 & 24 & 6.1 & 13.4 \\
\hline 20 & 18 & 22.4 & 22 & 24 & 5.6 & 13.5 \\
\hline 40 & 36 & 8.3 & 30.7 & 48 & 1.1 & 14.5 \\
\hline
\end{tabular}

Using multi-pulse rectifiers does indeed reduce the THDs as can be seen in Table II and Fig. 12. However, phase-shifting transformers and, often, a larger number of diodes are required which add to system mass and volume.

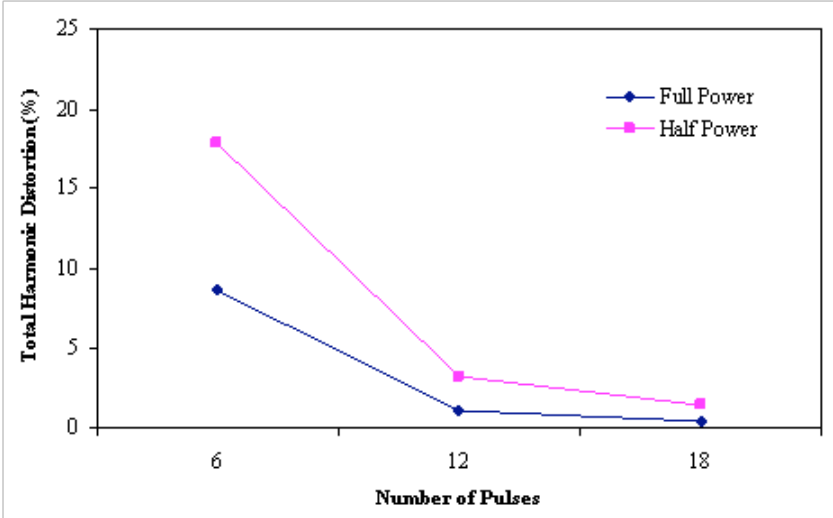

Fig. 12. Current THD vs. rectifier topology for the $40 \mathrm{MW}$ unit.

Finally, the 5 and 40 MW directly-coupled gas turbinepermanent magnet generator sets with 12-pulse rectifiers are shown in Fig. 13 for comparison and as models of potential prime power generating units in future all-electric ships.

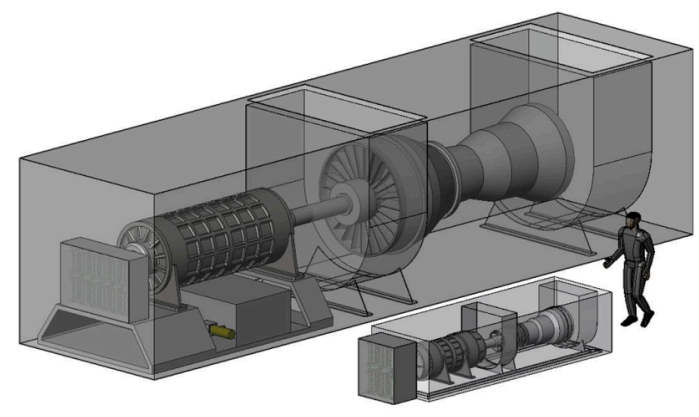

Fig. 13. 5 and $40 \mathrm{MW}$ directly-coupled gen-sets.

\section{GEN-SET LOCATION}

A previous work on the location of prime power generation units showed that installing the gas turbine gensets closer to the upper deck of an aircraft carrier does indeed save space [11]. In the following analysis four directly-coupled gas turbine-permanent magnet generator sets (totaling $80 \mathrm{MW}$ ) were chosen for installation on a notional all-electric destroyer in order to determine their relative size with respect to the ship and study possible configurations that allow space savings. These are: $5 \mathrm{MW}$, $15 \mathrm{MW}, 20 \mathrm{MW}$, and $40 \mathrm{MW}$ gen-sets. The ship model was built using public information obtained from various sources. Fig. 14 (which is to scale) clearly shows the relative sizes between ship and the $80 \mathrm{MW}$ prime power generation system. As can be seen on Fig. 15, the two large gen-sets are installed on the lower deck, requiring long air ducts to span all ship deck levels with a length of about 12 $\mathrm{m}(40 \mathrm{ft})$ each.

By installing these gen-sets on a higher deck level, the air

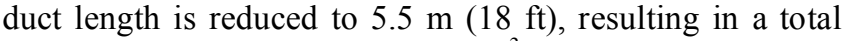
volume reduction of about $64 \mathrm{~m}^{3}$ - a very significant savings. The corresponding installation is shown in Fig. 16. The $5 \mathrm{MW}$ gen-set is installed on the highest deck level to indicate the possibility of eliminating most of the ducts and save maximum space. This may be possible since the low power gen-set is small enough in weight and volume not to cause any instability problems. The $15 \mathrm{MW}$ mid-size genset is installed at a position where the air ducts are also short. The actual installation of the prime power generation system onboard future all-electric ships is probably different from the one shown in this analysis, but this study illustrates the importance of gas turbine air ducts on power density and the possibility to reduce their volume by locating the prime power gen-sets on the highest deck levels possible. The stability concerns raised by this topology can be addressed in several ways, including the option of installing the large and heavy propulsion motors and their drives on the lowest deck since they don't require air ducts. This analysis provides the ship designer with quantitative information concerning the gain in volume that can be made using a specific prime power generation system such as the directly-coupled gas turbine-permanent magnet generator sets used in this study.

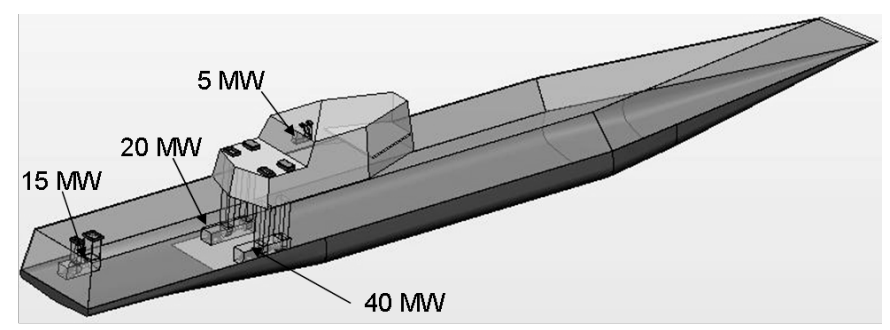

Fig. 14. $80 \mathrm{MW}$ directly-coupled gas turbine-PM generator set in future electric ship. 


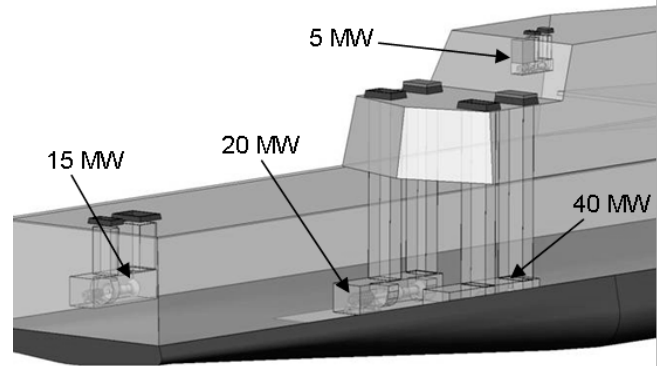

Fig. 15. Large gen-sets on lower deck level with long air ducts.

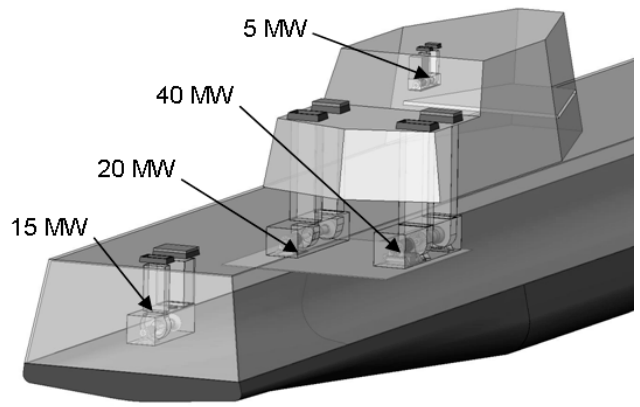

Fig. 16. Large gen-sets on higher deck level with short air ducts.

\section{Fuel CONSUMPTION ANALysis}

The next analysis performed involved determining the most efficient $80 \mathrm{MW}$ gen-set system to power an electric ship with a known or pre-determined mission profile. The combinatory analysis method developed determines the required power level for each gas turbine for a given segment of the mission profile to minimize fuel consumption over the whole mission. In the initial calculation, the program is set up to accept a given number of gas turbines, each with known power capacity and known specific fuel consumption characteristics. The calculation uses an actual mission profile for present-day destroyers (DDG-51) which was limited to a 24-hour period. The DDG-51 mission profile is shown in Fig. 17 and the corresponding power demand profile is in Fig. 18. The propulsion power demand used in the calculation is that of the notional DD electric ship and has a cubic dependence on speed, while the ship service power was fixed during the duration of the mission to $8 \mathrm{MW}$. Table III contains results of an analysis of three groups of gen-sets each totaling $80 \mathrm{MW}$. The calculation shows that fuel consumed by the system considered earlier in the air duct analysis $(5,15,20$, and 40 MW) is less than that consumed by a system made of four 20 MW gen-sets as well as the system used in the notional DD electric ship (4, 4, 36, and $36 \mathrm{MW})$. In addition, the calculation determines which gen-sets are used and at what power level during each segment of the mission. Details of the analysis can also be found in [6]. The calculation can be extended to accept any number of prime power units, with any power level, as long as fuel consumption characteristics for each unit are known. This analysis can also be useful to the electric ship power system designers to determine fuel consumption performance when deciding among several options for prime power generation in terms of number of units and the power level of each unit. In addition, once the number of units and their respective powers have been decided, the mode of operation can be determined by indicating which and how each gen-set is to be used to provide power for a given load.

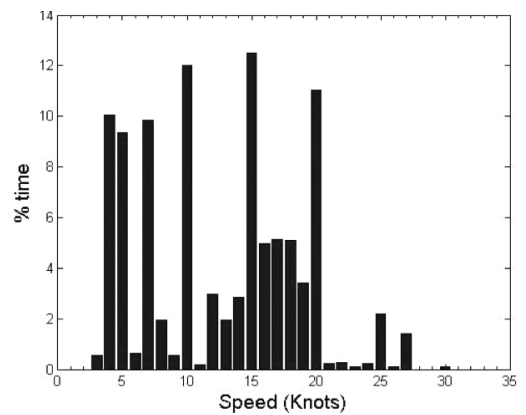

Fig. 17. Mission profile used in the calculation.

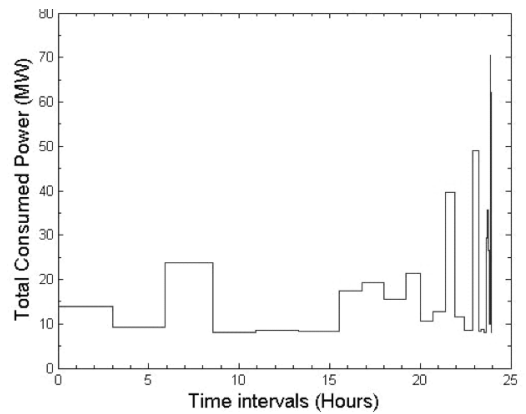

Fig. 18. 24-hour power consumption profile.

TABLE III

FUEL CONSUMPTION FOR THREE 80 MW GEN-SET SYSTEMS.

\begin{tabular}{|c|c|c|c|c|}
\hline \multicolumn{4}{|c|}{$\begin{array}{c}\text { Combination } \\
(\mathrm{MW})\end{array}$} & $\begin{array}{c}\text { Fuel } \\
\text { Volume } \\
\left(\mathrm{m}^{3}\right)\end{array}$ \\
\hline 5 & 15 & 20 & 40 & 101 \\
\hline 20 & 20 & 20 & 20 & 112 \\
\hline 4 & 4 & 36 & 36 & 117 \\
\hline
\end{tabular}

\section{CONCLUSION}

The directly-coupled gas turbine-permanent magnet generator topology has a potential of allowing space and weight savings on future all-electric ships. The permanentmagnet generators also allow an improvement in efficiency as compared to traditional wound-field generators. For specific ship missions, the choice of the number of power generation units, their individual power ratings, as well as their mode of operation have a direct impact on fuel consumption and an optimum combination can be determined. Further issues that have not been addressed in details in this paper: mainly the inability to control the PM generator voltage and the risk of permanent demagnetization under fault conditions. These will be considered in future work. 


\section{REFERENCES}

[1] N. McCallum, C. English, and B. Watier, "Development of the Advanced Cycle Low-Power Gas Turbine Alternator (ACL GTA)", GT2004-54302; in Proc. 2004 ASME Turbo Expo, GT2004-54302, pp. 1891-1899.

[2] L. Offringa and A. Blokland, "High-speed permanent-magnet generator with power electronic converter for gas turbine power plants", in Proc. 1998 IMarEST All-Electric Ship conf., pp. 75-80.

[3] C. Huynh, L. Hawkins, A. Farahani, and P. McMullen, "Design and development of a two- megawatt alternator for shipboard application" in Proc. 2004 Electric Machine Technology Symposium.

[4] R.M. Calfo, D.H. Clayton, M.B. Smith, and T.O. Zavertnik, "Highspeed generators for power dense, medium power, gas turbine generator sets," in Proc. 2006 IMarEST Engine As A Weapon II conf. pp. 31-40.

[5] K. Pesyna, R. Hebner, A. Ouroua, R. Thompson, and E. Bowles, "Highspeed generator options for direct coupled gas turbine flight and ground based power system", presented at the $8^{\text {th }}$ Annual Directed Energy Professional Society Symposium, Hawaii, USA, 2005.

[6] S. Vijlee, "Optimizing a system of gas turbine engines and generators for marine power generation," Master thesis, The University of Texas at Austin, May 2006.

[7] Gas Turbine World: 2003 GTW Handbook, Volume 23; Pequot Publishing; 2003.

[8] R. Berridge et al., "AC or DC for electricity distribution to ship services?” in Proc. 1998 IMarEST All-Electric Ship conf., pp. 25-32.

[9] J.V. Amy et al. "Shipboard electric power distribution: AC versus DC is not the issue," in Proc. 1998 IMarEST All-Electric Ship conf., pp. 33-41.

[10] http://www.infineon.com/upload/Document/high_power_semiconductor s/scr_diode_discs/d_2601n.pdf.

[11] R. Bannister and D. Horazak, "Preliminary assessment of advanced gas turbines for CVX," in Proc. 1998 ASME International Gas Turbine and Aeroengine Congress and Exhibition, pp. 1-8.

\section{Biographies}

S.Z. Vijlee has BS and MS degrees in mechanical engineering from The University of Texas at Austin where he contributed to this study. He is currently employed by the Boeing Company in Seattle, Washington where his work focuses on efficient power for aircrafts.

A. Ouroua obtained his $\mathrm{PhD}$, MS, and BS degrees in physics from The University of Texas at Austin, the University of California at Los Angeles, and the University of Science and Technology of Algiers respectively. His present work concentration is on EM design and analysis of electric machines.

L.N. Domaschk holds a Bachelor of Science degree in electrical engineering from The University of Texas at Austin. Her work interest is in power systems and power electronics.

J. H. Beno has BS and MS degrees in engineering physics and a $\mathrm{PhD}$ in electrical engineering. He is an Associate Director at The University of Texas at Austin Center for Electromechanics where he leads programs in electric vehicles, electric ship technology, and advanced vehicular suspension systems. 